
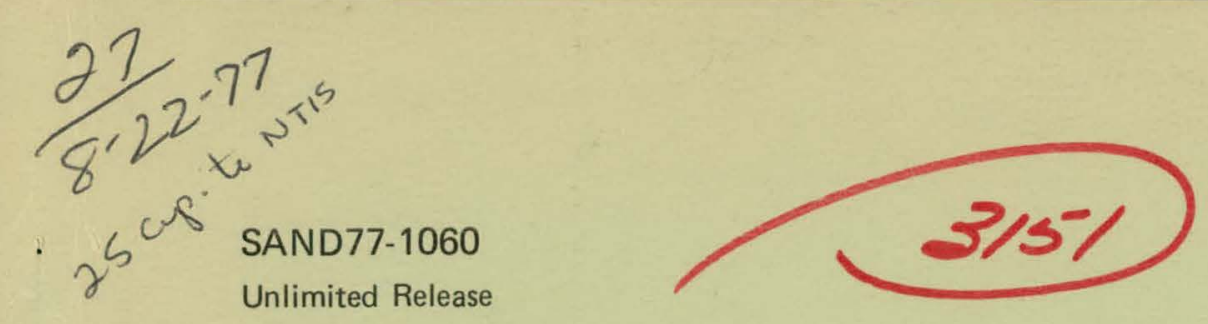

\title{
SPTH3: A Subroutine for Finding Shortest Sabotage Paths
}

Bernie L. Hulme, Diane B. Holdridge

Prevared by Sandia Laborataries. Albuquerque, New Mexico 87115

and Livermare, California 94550 for the United States Nuclear

Regulatory Cammission under ERDA Contract AT (29-1)-789

Printed July 1977

$2 \alpha$ 


\section{DISCLAIMER}

This report was prepared as an account of work sponsored by an agency of the United States Government. Neither the United States Government nor any agency Thereof, nor any of their employees, makes any warranty, express or implied, or assumes any legal liability or responsibility for the accuracy, completeness, or usefulness of any information, apparatus, product, or process disclosed, or represents that its use would not infringe privately owned rights. Reference herein to any specific commercial product, process, or service by trade name, trademark, manufacturer, or otherwise does not necessarily constitute or imply its endorsement, recommendation, or favoring by the United States Government or any agency thereof. The views and opinions of authors expressed herein do not necessarily state or reflect those of the United States Government or any agency thereof. 


\section{DISCLAIMER}

Portions of this document may be illegible in electronic image products. Images are produced from the best available original document. 
This report was prepared as an account of work sponsored by the United States Government. Neither the United States nor the United States Energy Research and Development Administration, nor the United States Nuclear Regulatory Commission, nor any of their employees, nor any of their contractors, subcontractors, or their employees, makes any warranty, expressed or implied, or assumes any legal liability or responsibility for the accuracy, completeness or usefulness of any information, apparatus, product or process disclosed, or represents that its use would not infringe privately owned rights. 
SAND $77-1060$

Unlimited Release

Printed July 1977

SPTH3: A SUBROUTINE FOR FINDING SHORTEST SABOTAGE PATHS

Bernie L. Hulme
Numerical Mathematics Division
Diane B. Holdridge
Applied Mathematics Division
Sandia Laboratories
Albuquerque, New Mexico 87115

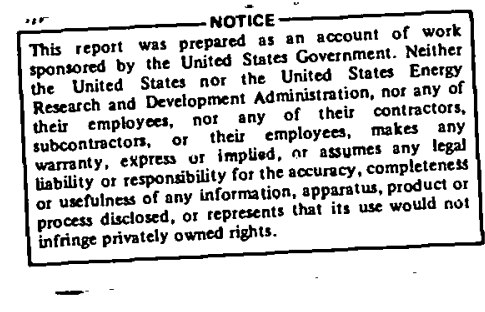

ABSTRACT

This document explains how to construct a sabotage graph which models any fixed-site facility and how to use the subroutine.SPTH3 to find shortest paths in the graph. The shortest sabotage paths represent physical routes through the site which would allow an adversary to take advantage of the greatest weaknesses in the system of barriers and alarms. The subroutine SPTH3 is a tool with which safeguards designers and analysts can study the relative effects of design changes on the adversary routing problem. In addition to showing how to use SPTH3, this report discusses the methods used to find shortest paths and several implementation details which cause SPTH3 to be extremely efficient.

\footnotetext{
+Presently in Nuclear Waste Technology Division.
}

Printed in the United States of America

Available from

National Technical Information Service

U.S. Department of Commerce

5285 Port. Royal Road

Springfield, Virginia 22161

Price: $\$ 4.00$ Microfiche $\$ 3.00$

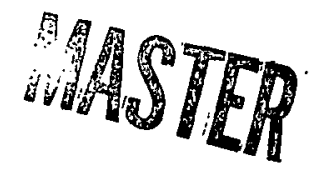


Page

1. Introduction • • • • • • • • . • . • . • 3

2. Description of SPTH3 • . . . . . . . . . . . 4

3. The Sabotage Graph • • . . . . . . . . . 5

3.1. The Regions . . . . . . . . . . . 6

3.2. The Graph G . . . . . . . . • . . 6

3.3. The Weights . . . . . . . . . . . 9

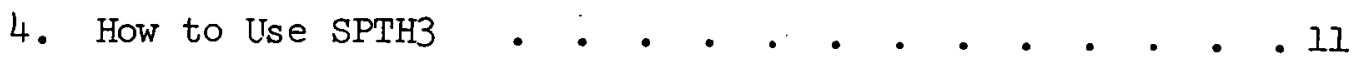

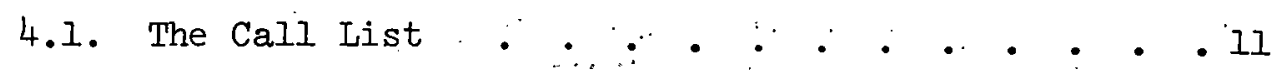

4.?. Input . . . . . . . . . . . 12

4.3. Work Arrays . . . . . . . . . . . . 13

4.4. Output . . . . . . . . . . . . . . 13

5. Examples •. • . • . • . . . . . . . . 14

5.1. A Sample Prrihlem : . . . . . . . . 74

5.2. Run l'ıme and Array Storage Results .. . . . . 16

6. Some Details of Tomplementation . . . . . . . . 18

6.1. A Flow Chart . • . . . . . . . . . . 18

6.2. The Triangle Inequality Tests . . . . . . 19

6.3. Computing Direct Distances . . . . . . . 20

6.4. Storing and Accessing Direct Distances . . . 20

6.5. The Difkstra-Yen Search. . . . . . . . 22

6.6. Retracing the Shortest Paths . - . . : : 24

6.7. Counting the Shortest Pathe . . . . . . . 25

7. Listing of SPTH3 • . . . . . . . . . . . 26 


\section{Introduction}

This report documents the latest code for finding shortest paths in the sabotage graphs described in [4]. A sabotage graph is a network which models a fixed-site facility. Shortests paths in the graph represent physical routes along which a saboteur could minimize time, or detection probability, or some other quantity reflected in the graph weights. Currently path length in SPTH3 is the ordinary sum of the node and arc weights in the path, so that either delay times (for barrier penetration at nodes and travel along ares) or else distances could be used as weights. So far shortest-time paths have been of principal interest. A trivial modification to SPTH3 would allow it to accept detection probability weights and produce sabotage paths which minimize cumulative detection probability. In the remainder of the report we shall think of the graph weights as times.

SPTH3 addresses the problem of a simultaneous attack by several teams each having a single target. This provides a lower bound for the path length of a single team with several targets to attack. sequentially, and it also addresses a very real possibility which would place great stress upon the safeguards system. For further details motivating this model and considering the length-independence of different shortest-time paths, see. $[4]$.

It must be understood that the graph model and the pathfinding techniques do not take into account battles between adversaries and defenders. Such encounters require stochastic models. The sabotage graphs used for pathfinding have constant weights which give representative (perhaps minimum or average) values of delay times. Since the delay times are in reality random variables, the graph-theoretic method of this 
report should be viewed as a deterministic approach to finding sabotage routes which exploit any weaknesses in the barrier and alarm systems. Such paths require further evaluation either by simulation methods such as FESEM [2] to assess the paths' effects upon guard encounters or else by probabilistic methods such as EASI [I] to predict the likelihood of sabotage interruption. Both of these path evaluators require a path to be given. Thus, SPTH3 may be used to derive input for FISEM or LAOI or. else simply tin inficate rclative vuluerdullities in the barrier and alarm systems.

This document explains both what SPTH3 does and how to use it. Those readers interested only in how to use it may ignore section 6 . The shortest path algorithm embedded in SPTH3 is that of Dijkstra [3] as modified by Yen $[6,5]$. This algorithm is the best available. However, its use in SPTH3 differs somewhat from the description given in [4]. Kather than searching outward to the boundary from each target as described In [4], SPTH3 searches inward from the boundary to all nodes. A substantial reduction in storage requirements and tenfold reductions in run time have resulted from this and other improvements to the pathfinding code.

\section{Degcription of SFTH3}

SPTH3 finds shortest paths in a special graph called a sabotage. graph. This graph models a fixed-site facility to some level of detail thought to be appropriate for the user's purpose. The details for conotructing the graph are given in the next section. In bricf, the nodes are important locations in the plant (say, perimeter gates, building doors, windows, vents, stairwells, storage vaults, and vital equipment locations), and the arcs are physical paths from one location to another. 
There are three types of nodes: (i) boundary nodes located at possible perimeter penetration points, (ii) barrier nodes located on internal barriers at possible penetration points, and (iii) target nodes* at vital equipment or material locations. The simultaneous sabotage problem is to find all the shortest paths from the set of boundary nodes to each target. Given the graph (as a list of arcs) and the arc and node weights, SPTH3 uses the Dijkstra-Yen algorithm described in Section 6.5 to search from the boundary nodes of the graph until the lengths of the shortest paths to all the other nodes are known. During the search SPTH3 keeps a list of the immediate predecessor(s) of each node along a shortest path from the boundary. This allows all shortest paths to each target to be retraced and stored without further arithmetic following the DijkstraYen search.

The output from SPTH3 is simply a list of the directed arcs which belong to the shortest paths directed from the boundary to all the targets, together with a list of the number and length of the shortest pathe to each target. It is possible to have more than one shortest path to any node, and this number can be obtained easily by a simple procedure explained in Section 6.7 .

\section{The Sabotage Graph}

The first and most important part of the use of SPTH3 is the construction and weighting of the sabotage graph. This involves three steps:

(1) partitioning the drawings of the plant into regions,

*Formerly called hardware nodes. 
(2) specifying the nodes and arcs of the graph model,

(3) weighting the nodes and arcs with times (or detection probabilities) derived from test data or analyst judgement.

\subsection{The Regions}

The boundary and the important internal barriers (fences, walls, floors, stairwells, etc.) naturally partition a map of the site into regions $R_{r}, r=1,2, \ldots$. A region is a very general area within which saboteurs may trave1. unimpodod by barriers. Some regions may appear on the drawing as disjolnt domains, e.g., a stairwell or elevator region may appear as the union of the areas in which it intersects each floor of. a building. However, if there are no significant delays to entering the stairwell, then the floors and the connecting.stairwell may be treated as one region. The region structure is simply an aid to constructing the nodes and arcs which constitute the sabotage graph.

\subsection{The Graph $G$}

Next, the analyst must carefully place nodes at all the important locations. Since the model is discrete there is some arbitrariness in the node selection process, and an analyst may want to try various graphs differing in the number and location of the nodes. The nnie sot ohould include representative penetration points along the boundary and along the barriers between regions as wcll as all largets of interest inside the regions.

Once the regions and the nodes are specified, the arcs are determined by a fixed rule which gives sabotage graphs their special structure. Every pair of nodes in region $R_{r}$ is connected by an arc, forming a complete subgraph $G_{r}, r=1,2, \ldots$. 
An interface between two regions may contain more than one barrier node, and this requires special attention from the analyst. Two reasons for using such multiple barrier nodes are to model barriers that (a) have varying hardness, or (b) have such physical extent that the arc lengths are significantly affected by the node locations. An arc joining node $i$ to node $j$ is denoted by the unordered integer pair $(i, j)$ or $(j, i)$. Multiple barrier nodes on a singie barrier cause an arc in one region to have the same name, or node pair, as some arc in the adjacent region (Figure la). In order that each arc have a unique node pair as its endpoints, the analyst must split each of the multiple barrier nodes into two barrier nodes connected by an arc (Figure lb). Our decision to list the arcs of G region by region for purposes of. computer input requires that each arc belong to a single region. Consequently each arc introduced by splitting multiple barrier nodes must belong to its own specially created region.

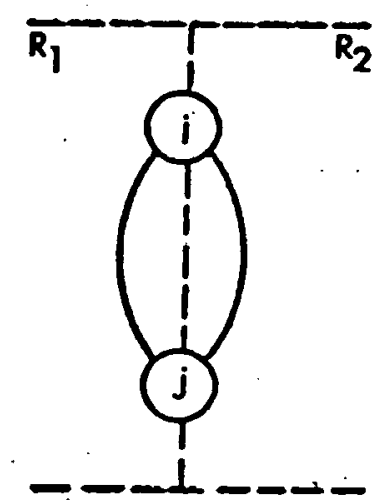

Tigure la. Multiple barrier nodes.

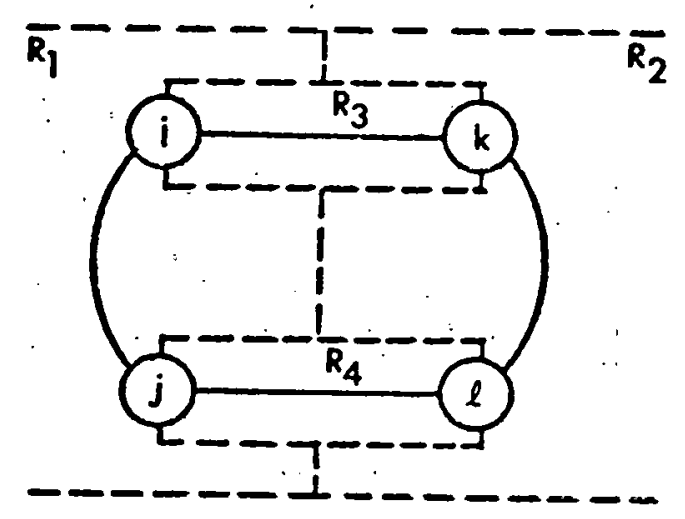

Figure lb. Splitting of multiple barrier nodes.

The regions created by splitting multiple barrier nodes are numbered also, giving a total of $N_{R}$ regions $R_{r}$, each having a complete subgraph $G_{r}$ 。 
The union of all these subgraphs is the sabotage graph*

$$
G=\bigcup_{r=1}^{N_{R}} G_{r},
$$

whose nodes are then numbered as follows:

$$
\begin{aligned}
& \text { target nodes, } 1 \text { to } n_{1} \text {, } \\
& \text { barrier nodes, } n_{1}+1 \text { to } n_{1}+n_{2} \text {, } \\
& \text { boundary nodes, } n_{1}+n_{2}+1 \text { to } n_{1}+n_{2}+n_{3}=N
\end{aligned}
$$

An example is shown in Figure 2, where squares are used for boundary nodes, circles for barrier nodes, and shaded circles for targets. Three nodes on the barrier $R_{1} \cap R_{2}$ have been split.

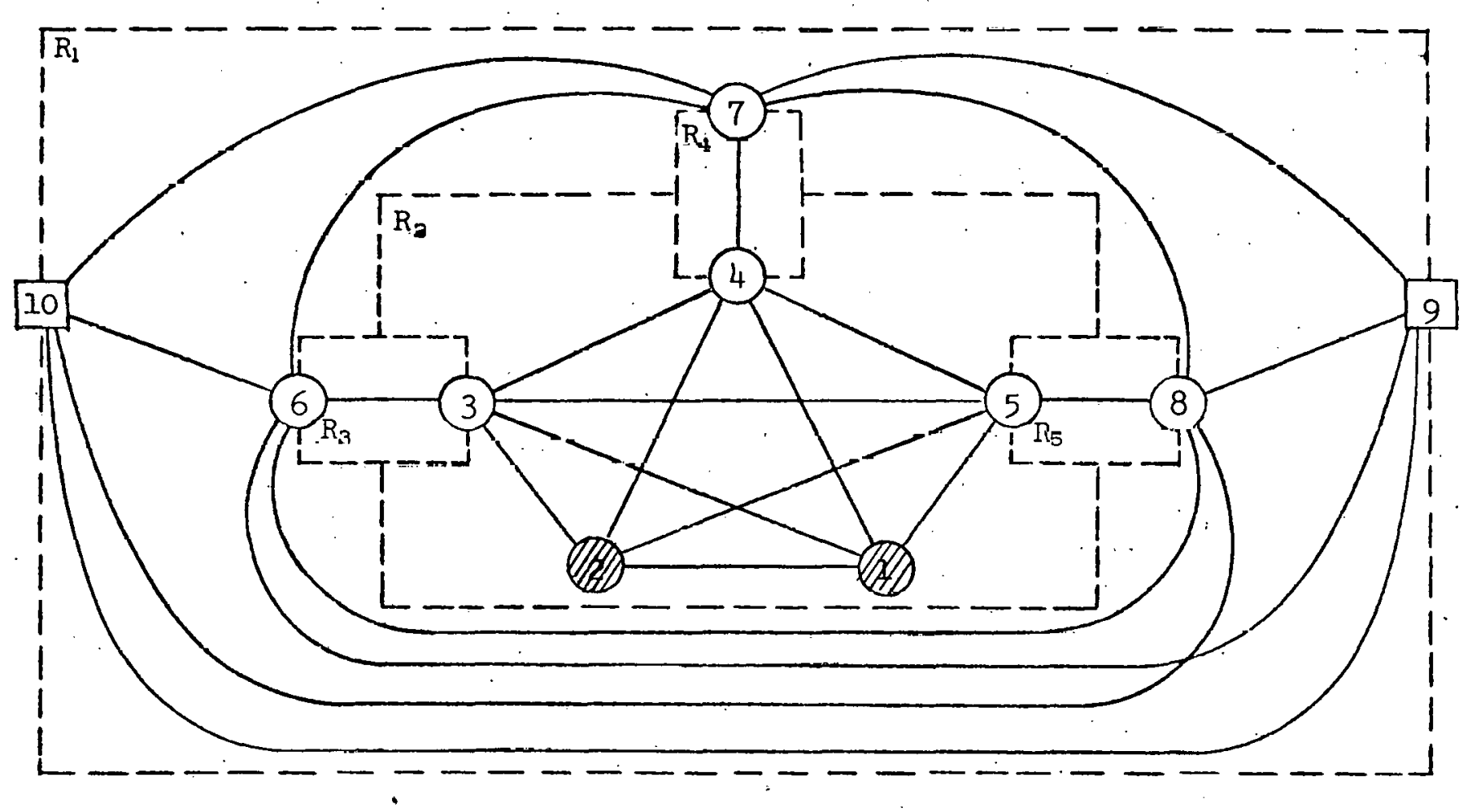

Figure 2.

A Sabotage Graph

*This graph differs slightly from the graph of [4] in which boundaryboundary and target-target arcs were omitted. 
Notice that every barrier and boundary node belongs to exactly two regions (counting the infinite off-site region), and every target node belongs to only one region. Also, due to the completeness of the subgraphs, the paths of $G$ represent all the physically meaningful ways for saboteurs to proceed using only the given penetration points and targets.

\subsection{The Weights}

Both the nodes and the arcs of $G$ are assigned constant, nonnegative weights. The node weights $w_{i} \geq 0, I \leq i \leq N$, are penetration and target destruction times, while the arc weights $a_{i, j}=a_{j, i} \geq 0,(i, j) \& G$, are transit times. Realizing that these constants are simply representative values of random variables that depend on the physical characteristics of the barriers and the amount and type of equipment postulated for the attacking force; the analyst must decide whether to be conservative and use minimum values reflecting best possible adversary performance or else use intermediate or average values.

When the arc weights are minimum values, they will automatically satisfy a regional triangle inequality. That is, if $\operatorname{arcs}(i, j),(j, k)$ and $(k, i)$ belong to $G_{r}$ and their weights represent minimal transit times, then it must be true that

$$
a_{i, k} \leq a_{i, j}+a_{j, k}
$$

Since saboteurs may travel at different rates in different regions, this inequality need not hold for triangles whose arcs lie in different regions. SPTH3 tests all the triangle inequalities (1) for each region simply as a check on data consistency for the user's benefit. The pathfinding algorithm will perform perfectly well, of course, whether or not the triangle inequalities hold, so that this data check can be deleted from 
SPTH3.

The weighting of the nodes and arcs which result from the splitting of multiple barrier nodes may be done in many ways as long as the weights of the two new nodes and their connecting arc sum to the barrier penetration time.

A weighting of the graph from Figure 2 is given in Figure 3.

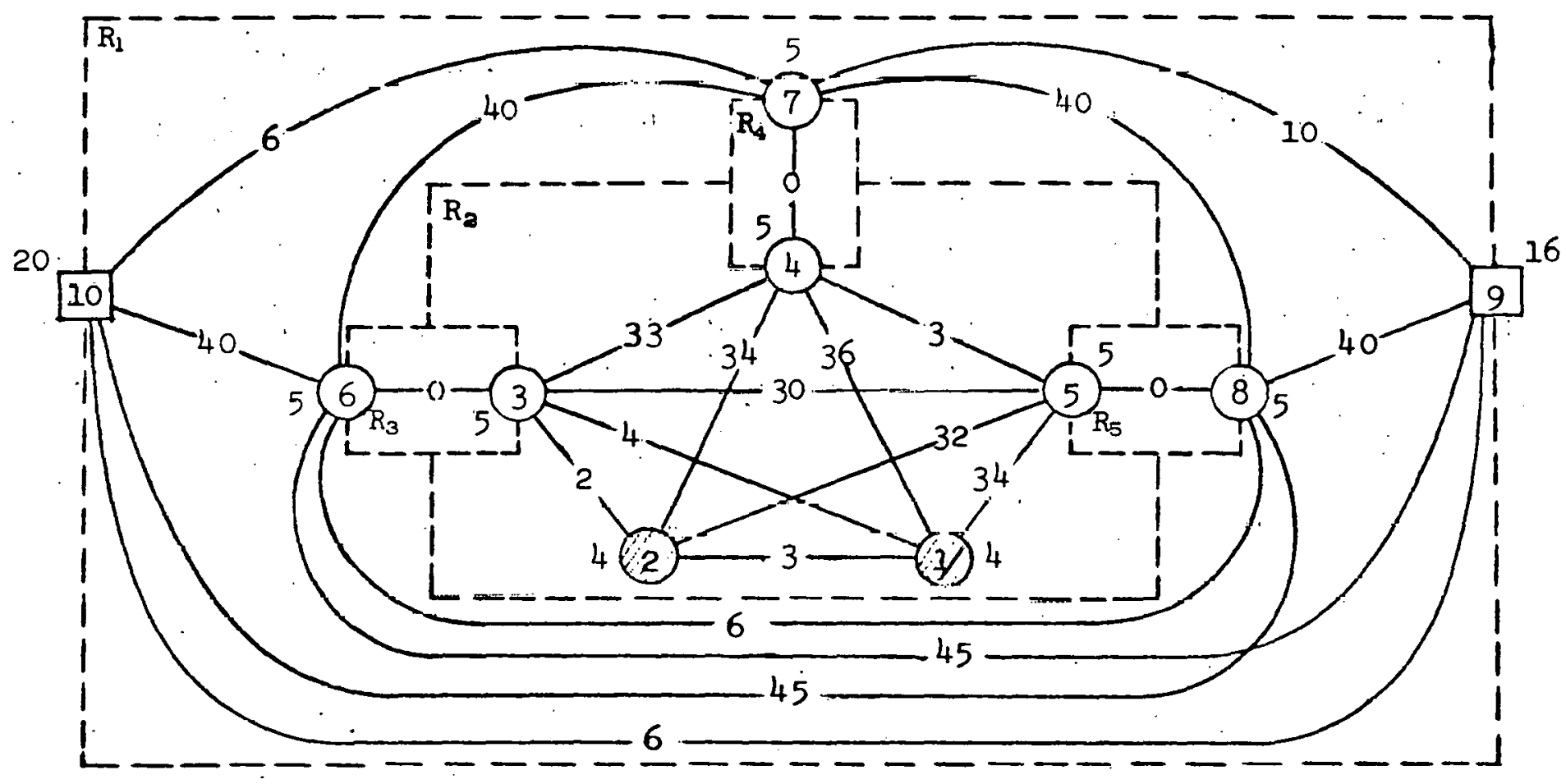

Figure 3.

A Weighted Sabotage Graph

SPTH3 does not accept directed nodes and arcs, i.e., nodes and arcs whose weights depend on the direction of travel. Of course, directed nodes and arcs could have been allowed, because Dijkstra's algorithm works equally. well for directed graphs (digraphs) as for undirected graphs. However, we have deliberately omitted directedness from the sabotage 
graphs because, in the applications for which SPTH3 is intended, arc lengths are essentially the same in both directions and the doors locked on only one side are normally locked on the side first encountered by the saboteur.

\section{How to Use SPTH3}

\subsection{The Call List}

The call list for subroutine SPTH3 is

$$
\mathrm{SPTH} 3(\mathrm{NI}, \mathrm{N} 2, \mathrm{~N} 3, \mathrm{NA}, \mathrm{W}, \mathrm{MR}, \mathrm{II}, \mathrm{JJ}, \mathrm{AWT}, \mathrm{MAXE}, \text { IEDGE , NE , NSP , XMINL). }
$$

The dummy arguments have the following meanings:

$$
\begin{aligned}
& \text { N1 - the number of target nodes, } \\
& \text { N2 - the number of barrier nodes, } \\
& \text { N3 - the number of boundary nodes, } \\
& \text { NA - the number of arcs, } \\
& \text { W(.) - the node weight vector, dimensioned } N=N 1+N 2+N 3 \text {, }
\end{aligned}
$$

(the next four vectors, dimensioned NA, give the arcs as quadruples consisting of a region, two nodes, and an arc weight)

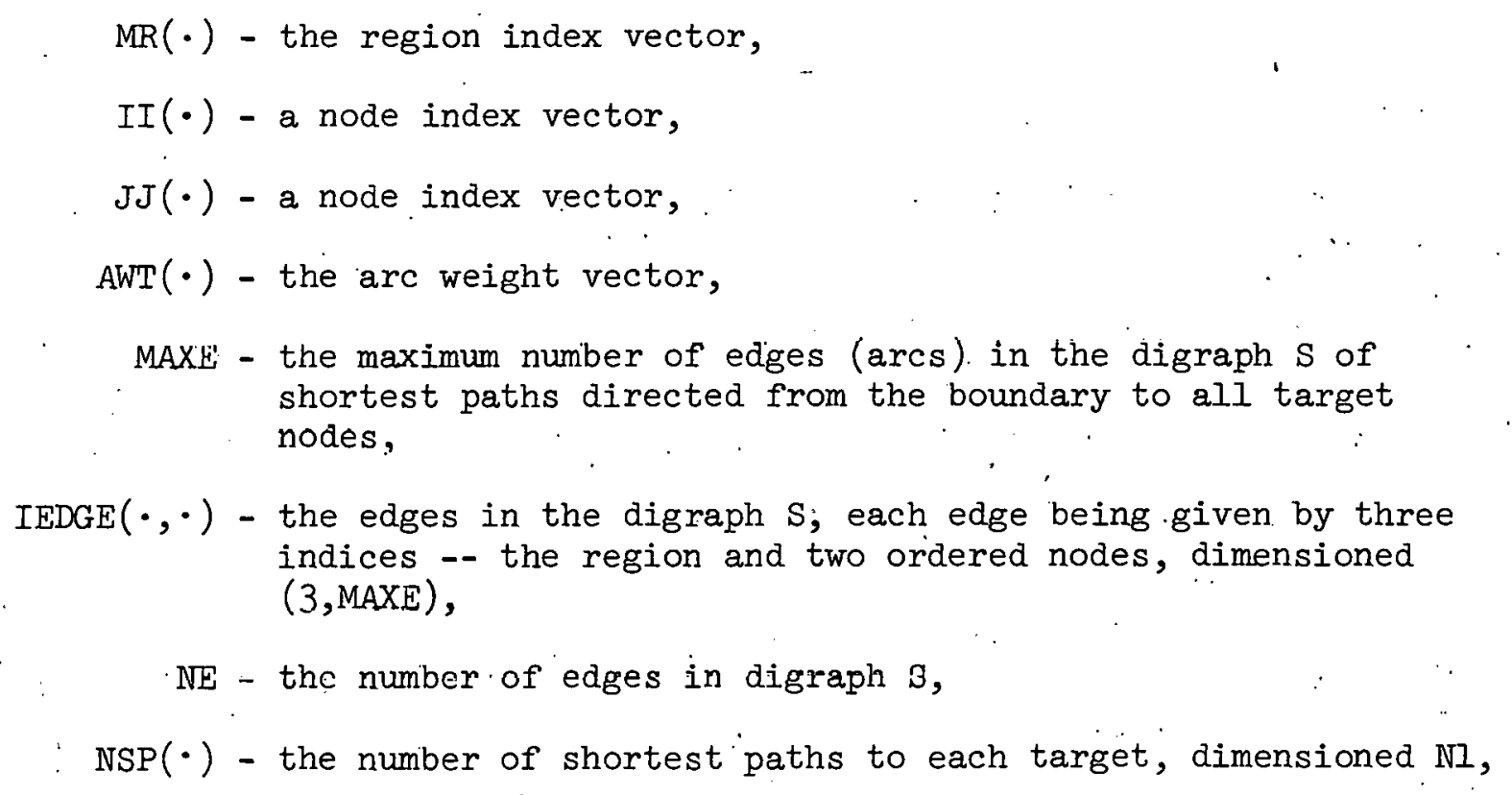
shortest paths directed from the boundary to all target nodes,

$\operatorname{IEDGE}(\cdot, \cdot)$ - the edges in the digraph $S$; each edge being given by three indices -- the region and two ordered nodes, dimensioned $(3, \mathrm{MAXE})$,

NE - the number of edges in digraph 3 , $\operatorname{NSP}(\cdot)$ - the number of shortest paths to each target, dimensioned NI, 
XMINL(•) - the length of the shortest paths to each target, dimensioned NI.

\subsection{Input}

To use SPTH3, first construct a weighted sabotage graph as indicated in section 3. Next, in the program which calls SPTH3, dimension $W$ by $N$, the vectors $M R$, II, JJ and AWT by NA, and the vectors NSP and XMINL by NI. Set MAXE to some guess at the maximum number of edges $S$ will have, and dimension IEDGE by (3,MAXE). Then store the node weights in $\mathrm{W}$ and the arc data in MR, II, JJ and AWT. The node weights are given in the obvious order: $W(I)$ for node $I, I \leq I \leq N$. Although there is no obvious order. in which to give the arc data, a very special ordering of the arcs is required.

The arcs are given by the quadruples

$$
\mathrm{MR}(\mathrm{K}), \mathrm{II}(\mathrm{K}), \mathrm{JJ}(\mathrm{K}), \operatorname{AWT}(\mathrm{K}), I \leq \mathrm{K} \leq \mathrm{NA}
$$

All the arcs of one region are listed consecutively, and the regions may be given in any order. For example, in a three region problem, the arcs of region two could be listed first, followed by the arcs of regions three and one. The arcs of each region, however, must be listed as if they were taken row by row from the strictly upper triangular part of some node adjacency matrix. For example, if the nodes of one region are $\{16,9,21,4,7\}$, then an acceptable arc ordering based on the given node ordering is $(16,9),(16,21),(16,4),(16,7) ;(9,21),(9,4),(9,7),(21,4)$, $(21,7),(4,7)$. Notice that the arc ordering for a region may be based on any ordering of the region's nodes. But once a node ordering is chosen for the region, the arcs must be given by pairing the first node with each other node in order, then pairing the second node with each 
following node in order, and similarly. for the third node, etc.

The reason for this requirement is that it produces tremendous savings in storage. The special arc ordering allows SPTH3 to quickly compute the address of any arc weight and, thereby, completely eliminates the need for the usual $N \times \mathbb{N}$ direct distance matrix. For graphs with several hundred nodes this is very important.

\subsection{Work Arrays}

SPTH3 has several work arrays whose dimensions must be set by the user before running the job. The meanings of these arrays are explained in the program comments and in section 6 . In order to use SPTH3 it is sufficient for the user to set the following dimensions:

XLABEL, NPATH, IPERM, ITEMP, NEXT - N,

NODE - $(\mathrm{N}, 4)$,

IREG - $(\mathrm{NR}, 2)$, where NR = the number of regions,

NPOOI - 40, an arbitrary setting for an unpredictable total number of extra predecessors for nodes which have more than one predecessor along shortest paths. SPTH3 prints a message when this dimension needs to be increased. In this case, the results should be considered.incomplete, and the problem should be rerun with a larger dimension for NPOOL.

4.4. Output

The output consists of

$$
\text { MAXE, IEDGE, NE, NSP and XMINL, }
$$

whose meanings are given above.

MAXE and NE serve as flags and must be tested upon return from SPTH3 to see if a normal execution took place. If MAXE $=0$ upon return, there was a failure of the triangle inequality on the arc weights of some region, a message was printed, and the pathfinding algorithm was not 
executed. The user should correct the arc data indicated by the message and try again. Also, it is possible to return with $\mathrm{NE}=0$. This means that pathfinding was aborted because some node could not be reached from the boundary. The user must check the arc list to be sure that all the arcs are present in each region.

It should be noted that the weight vectors $W$ and AWT are changed by SPTH3 in the following way:

$$
\begin{gathered}
W(I)-W(I) / 2 ; N I+J<T<N+N P \\
A W T(K)-A W T(K)+W(I I(K))+W(J J(K)), \quad I \leq K \leq N A
\end{gathered}
$$

If necessary, the user may restore $W$ and AWT to their input values by first subtracting $W(I I(K))+W(J J(K))$ from $\operatorname{AWT}(K)$, for $I \leq K \leq N A$, and then doubling each barrier node weight. This change of $W$ and AWT is also related to the above mentioned storage economy because it allows the input vector AWT to be used for the direct distance storage in lieu of the standard $\mathrm{N} \times \mathrm{N}$ matrix normally used in Dijkstra's algorithm.

\section{Exampiles}

\subsection{A Sample Problem}

Let us take the weighted graph of Figure 3 as an example. In Figure 4 this graph is shown with the digraph $S$ of shortest sabotage paths superimposed in dark lines.

The input consists of

$$
\begin{aligned}
& \mathrm{N} 1=2, \mathrm{~N} 2=6, \mathrm{~N} 3=2, \quad \mathrm{NA}=23, \\
& \mathrm{~W}=\{4 \cdot, 4 \cdot, 5 ., 5 \cdot, 5 \cdot, 5 \cdot, 5 ., 5 \cdot, 16,, 20 \cdot\},
\end{aligned}
$$




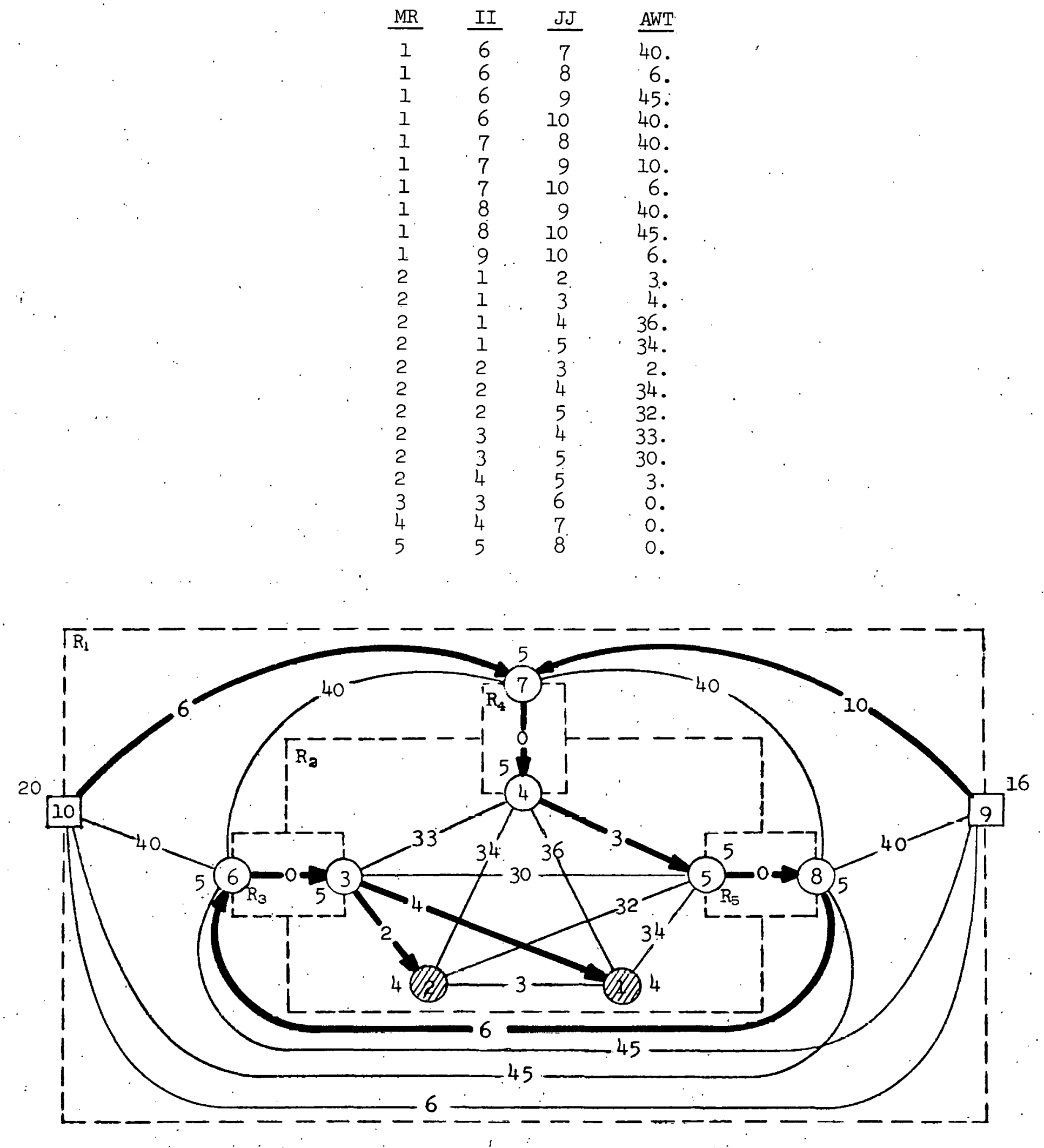

Figure 4.

The Digraph $\mathrm{S}$ of Shortest Sabotage Paths Superimposed on a Weighted Sabotage Graph 
The output is

\begin{tabular}{|c|c|c|}
\hline Target & NSP & XMINL \\
\hline 1 & 2 & 73. \\
\hline 2 & 2 & 71 . \\
\hline \multicolumn{3}{|c|}{ IEDGE $(N E=9)$} \\
\hline Region & Node & Node \\
\hline-2 & 3 & 1 \\
\hline 2 & 3 & 2 \\
\hline 3 & $\overline{6}$ & 3 \\
\hline 1 & 8 & 6 \\
\hline 5 & 3 & 8 \\
\hline 2 & 4 & 5 \\
\hline 4 & 7 & 4 \\
\hline 1 & 10 & 7 \\
\hline 1 & 9 & 7 \\
\hline
\end{tabular}

. Since the digraph $\mathrm{S}$ is given completely by IEDGE, $\mathrm{S}$ is easily drawn by simply darkening the edges indicated by the ordered node pairs in IEDGE. NSP and XMINL show that there are two shortest paths to cach target, thooc to node 1 having length 73. and those to node 2 having length 71.

\subsection{Kun l'ime and Array Storage Results}

SPTH3 is extremely fast. The Dijkstra-Yen algori.thm used for pathfinding has a worst-case mun time on the order of $O\left(N^{2}\right)$ for an $N$-node graph. Although SPTH3 also checks all the triangle inequalities in each region, does the bookkeeping for multiple predecessors, and retrares and counts the number of shortest paths to each target, it uses almost a negligible amount of mun time. As shown in Table I a realistic sized problem of 310 nodes and 1191 arcs requires only about a second and a half of CDC 6600 mun time. Consequently, we feel that execution time for shortest path problems should be of very little concern to most users. SPTH3 is also very storage efficient. As mentioned in section 4.4, the $N \times N$ matrix of direct distances normally used in Dijkstra's algorithm 
has been eliminated in favor of a storage scheme which overwrites the input vector AWT with direct distances between node centers. Thus, the array storage, which dominates SPTH3's storage requirements for larger problems, is linear in the number of nodes, arcs, regions, etc. In parțicular SPTH3's arrays need

$$
1 \mathrm{ON}+4 \mathrm{NA}+2 \mathrm{NR}+2 \mathrm{NI}+3 \mathrm{NE}+40
$$

storage locations, where 40 is an unpredictable dimension that proved adequate for our set of test problems. Table I also gives the array storage requirements for the larger problems in the test set.

*The sample problem in Figure 4 is Problem 3 below.

Table I

CDC 6600 Run Time and Array Storage Results

\begin{tabular}{|c|c|c|c|c|c|c|c|}
\hline Problem & $N_{1}-N_{c}^{2}-N_{3}$ & $\begin{array}{l}\text { Nodes } \\
\text { N }\end{array}$ & $\begin{array}{l}\operatorname{Arcs} \\
\text { NA }\end{array}$ & $\begin{array}{c}\text { Regions } \\
\text { NR }\end{array}$ & $\begin{array}{c}\text { Edges in } \mathrm{S} \\
\mathrm{NE}\end{array}$ & $\begin{array}{l}\text { Array } \\
\text { Storage }\end{array}$ & $\begin{array}{l}\text { Run Time } \\
\text { (seconds) }\end{array}$ \\
\hline 1 & $1-5-1$ & 7 & 13 & 4 & 3 & - & 0.004 \\
\hline 2 & $5=1-2$ & 8 & 16 & 2 & 6 & $=$ & 0.004 \\
\hline 3 & $2-6-2$ & 10 & 23 & 5 & 9 & - & 0.005 \\
\hline 4 & $4-8-2$ & 14 & $3 !$ & 6 & 12 & - & 0.007 \\
\hline 5 & $1-8-8$ & 17 & 32 & 8 & 1 & - & 0.009 \\
\hline 6 & $1-10-8$ & 19 & 40 & 8 & 1 & 411 & 0.009 \\
\hline 7 & $1-31-14$ & 46 & 112 & 20 & 2 & 996 & 0.041 \\
\hline 8 & $20-58-4$ & 82 & 514 & 35 & 43 & 3155 & 0.167 \\
\hline 9 & $30-120-5$ & 155 & 656 & 82 & 81 & 4681 & 0.446 \\
\hline 10 & $10-296-4$ & 310 & 1191 & 192 & 38 & 8422 & 1.563 \\
\hline
\end{tabular}




\section{Some Details of Implementation}

\subsection{A Flow Chart}

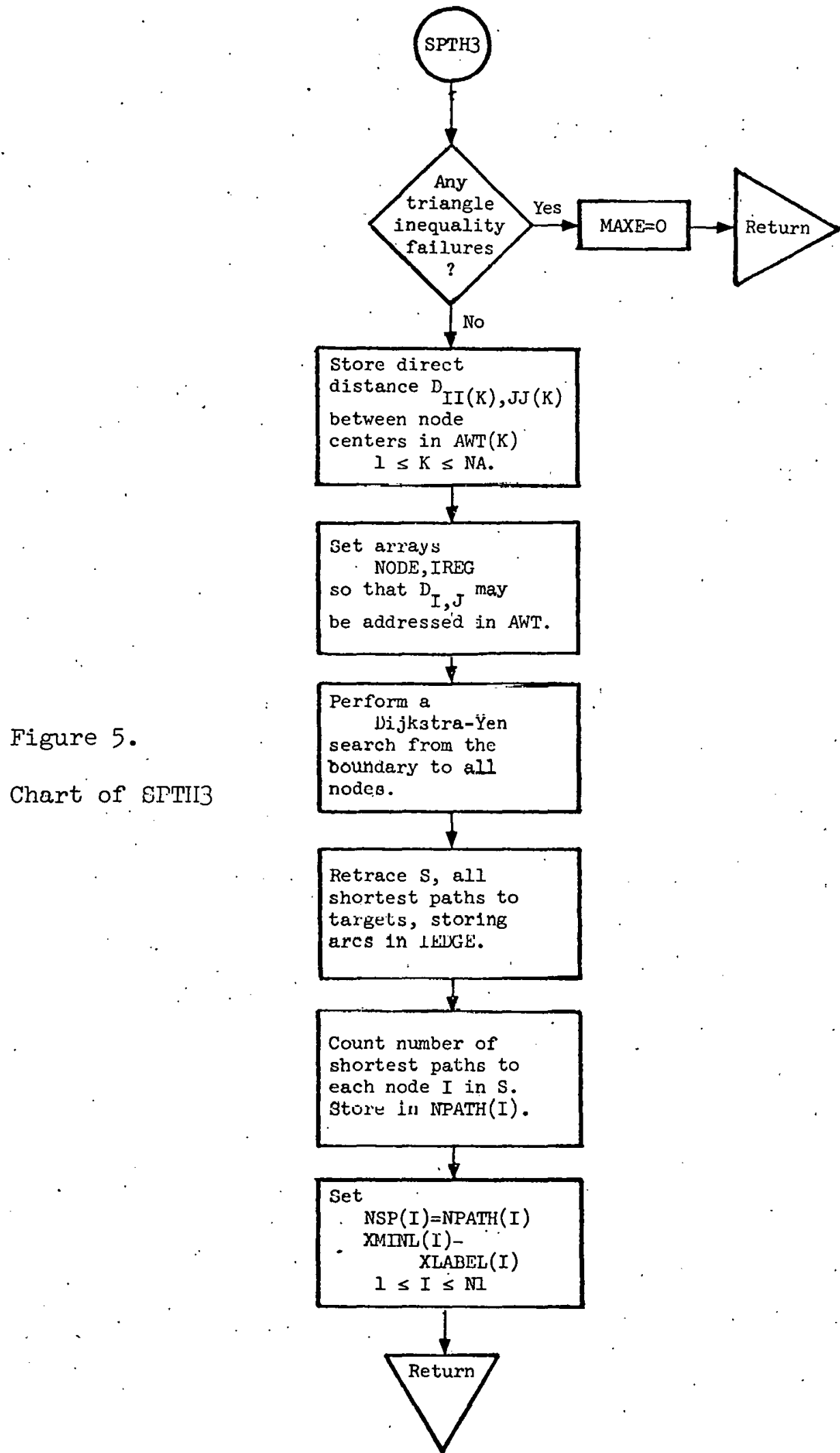




\subsection{The Triangle Inequality Tests}

Finding the triangles of each region is very easy given the completeness of the subgraph and the special ordering of the arcs. For example, consider the arcs of region $R_{2}$ in the graph of Figure 4 ,

$\begin{array}{ccc}I I & \text { JJ } & \text { AWT } \\ 1 & 2 & 3 . \\ 1 & 3 & 4 . \\ 1 & 4 & 36 . \\ 1 & 5 & 34 . \\ 2 & 3 . & 2 . \\ 2 & 4 & 34 . \\ 2 & 5 & 32 . \\ 3 & 4 & 33 . \\ 3 & 5 & 30 . \\ 4 & 5 & 3 .\end{array}$

All the triangles containing arc $(1,2)$ are found by taking each arc $(1, l)$ listed below $(1,2)$ together with each arc $(2, l)$. In this case, the triangles are $(1,2,3) ;(1,2,4)$ and $(1,2,5)$. Next, all the triangles containing arc $(1,3)$ are obtained by taking each arc $(1, l)$ listed below $(1,3)$ together with each arc $(3, l)$. This yields triangles $(1,3,4)$ and $(1,3,5)$. Finally; triangle $(1,4,5)$ is obtained in a similar way.

of course, each triangle $(i, j, k)$ has three corresponding inequalities which are tested separately

$$
\begin{aligned}
& a_{i, j} \leq a_{i, k}+a_{k, j}, \\
& a_{i, k} \leq a_{i, j}+a_{j, k}, \\
& a_{j, k} \leq a_{j, i}+a_{i, k} .
\end{aligned}
$$

As mentioned earlier, this portion of SPTH3 could be deleted without affecting the pathfinding procedure. 


\subsection{Computing Direct Distances}

Dijkstra's algorithm is defined in terms of a direct distance matrix D, whose elements

$$
d_{i, j}=\left\{\begin{array}{l}
\text { direct distance from } i \text { to } j,(i, j) \in G, \\
0, \quad i=j, \\
\infty, \text { otherwise. }
\end{array}\right.
$$

The algorithm applies to any digraph having weights only on the arcs, since the nodes are thought of as points. A sabotage graph has node weights $w_{i}$ which SPTH3 combines with the arc weights $a_{i, j}$ in forming the distances $d_{i, j}$ between node centers. The procedure is to halve the barrier node. weights (since these are the intermediate nodes on paths from the boundary to the targets) and then to add each arc weight to its endpoint weights, i.e.

$$
\begin{array}{r}
w_{i}=w_{i} / 2, n_{1}+1 \leq i \leq n_{1}+n_{2}, \\
a_{i, j}=a_{i, j}+w_{i}+w_{j},(i, j) \in G .
\end{array}
$$

\subsection{Storing and Accessing Direct Distances}

SPTH3 avoids creating the $N \times N$ matrix $D$ by storing the positive, finite, D values in the input arc weight vector AWT when (4) is computed, i.t

$$
I=I I(K), J=J J(K)
$$

$$
\operatorname{AWT}(K)=\operatorname{AWT}(K)+W(I)+W(J), I \leq K \leq N A
$$

This saves a great deal of storage for large $\mathbb{N}$ because the number of arcs in $G$ is always small with respect to $N^{2}$ (see Table I).

The penalty we pay for this storage efficiency is in the cost of finding any particular $d_{I, J}$ in AWT. That is, when Dijkstra's algorithm needs $d_{I, J}$, SPTH3 must find a value $K$ such that 


$$
\operatorname{AWT}(K)=d_{I, J}
$$

instead of just referencing $D(I, J)$. Fortunately, the completeness of the subgraphs and the special ordering of arcs in each subgraph allows $K$ to be computed very quickly given $I$ and $J$ (see the run times in Table $I$ ).

To facilitate this index computation, two integer arrays are constructed prior to the Dijkstra-Yen search. $\operatorname{NODE}(I, \cdot)$ contains the two regions and two local node numbers for node I. The local node number in each region is determined by the node ordering used to order the arcs of the region. For the sample problem in section 5.1,

$$
\operatorname{NODE}(7, \cdot)=\{1,2,4,2\},
$$

meaning that node 7 is the second node of region 1 and the second node of region 4. Since only the finite, internal regions are numbered, boundary nodes have only one region number and one local node number. Similarly for target nodes which belong to only one region.

$\operatorname{IREG}(\mathrm{R}, \cdot)$ contains the first word address minus one in AWT of the arcs of region $R$ followed by the number of nodes in $R$. Thus, when SPTH3 needs $d_{I, J}(I \neq J)$, it does the following:

(a) compares region numbers for $I$ and $J$ to see if arc $(I, J)$ belongs to $G$,

(b) if $(I, J) \notin G$, no address computation is needed since $d_{I, J}=\infty$,

(c) if $(I, J) \in G_{R}$, then the first word address minus one of the arcs of reyiun $R$, lhe number of nodes in region $k$, the local number of node $I$ in $R, l_{I}$, and the local number of node $J$ in $R, l_{J}$, are combined to yield

$$
K=\left\{\begin{array}{l}
\operatorname{IREG}(R, I)+\left(l_{I}-I\right) \operatorname{IREG}(R, 2)-l_{I}\left(\ell_{I}+1\right) / 2+l_{J}, l_{I} \leq \ell_{J}, \\
\operatorname{IREG}(R, I)+\left(l_{J}-I\right) \operatorname{IREG}(R, 2)-l_{J}\left(l_{J}+I\right) / 2+l_{I}, l_{J}<l_{I}
\end{array}\right.
$$

$\mathrm{K}$ satisfies (6). 


\subsection{The Dijkstra-Yen Search}

The Dijkstra-Yen search finds the length of the shortest paths from the boundary to every node $I$ in $G$ and stores the value in XMINL(I), $I \leq I \leq N$. During the search the (immediate) predecessor of node $J$ along a shortest path is stored in $\operatorname{NEXT}(J), I \leq J \leq N$. When some node has more than one such predecessor, the extras are stored in a vector NPOOL. A link (an index for NPOOL) is stored in the upper portion of the word NEXT(J) to indicate where the second predecessor of $T$ is stinren. This sesond. - predecessor, NPOOL(LINK), is linked to another entry in NPOOL if there is a third predecessor of $\mathrm{J}$, etc.* These data allow the efficient retracing of all (not just one) shortest paths to each target, as explained in the next section.

In Dijkstra's algorithm [3] each node has a label which eventually becomes the length of the shortest paths from the boundary to the node. Thiese lavels are tempoirary as Long as they represent only the shortest path lengths currently found by the search, and they become permanent labels as soon as they are known to be the absolutely shortest lengths.

SPTH3 initially sets all boundary node labels to zero and all other labels to $\infty$ (a large machine number). The boundary node label XIABEL(N) is made permanent first by setting $\operatorname{IPERM}(I)=N$. All the other labels are temporary. From the last permanently labeled node I, all the temporary labels $\mathrm{XLABEL}(\mathrm{J})$ are examined and reduced if

$$
\operatorname{XLABEL}(J)>\operatorname{XLABEL}(I)+d_{I, J}
$$

where $d_{I, J}$ must be found in AWT as described in the previous section. Each

*We are indebted to Louann Grady, 574l, for giving us this idea for linking together multiple predecessors. 
time $\mathrm{XIABEL}(\mathrm{J})$ is reduced, the predecessor $I$ is stored in $\operatorname{NEXT}(J)$. If

$$
\operatorname{XLABEL}(J)=\operatorname{XLABEL}(I)+d_{I, J},
$$

(to machine precision), then $I$ is an extra predecessor of $J$ which must be stored in the next available entry of NPOOL, and for which an additional link must be created at the end of the chain beginning with the link in the upper portion of $\operatorname{NEXT}(J)$. After all the temporary nodes have been examined from $I$, the one with the least temporary label is made permanent by placing it in IPERM. This is correct because the nonnegativity of the $d_{I, J}$ implies that this label cannot be reduced further. In the case of a tie, it does not matter which of the nodes is permanently labeled next. I is set to this new permanent node number and the process is repeated until all the nodes are permanently labeled. Notice that IPERM has become a list of the nodes of $G$ in order of nondecreasing distance from the boundary, and the shortest sabotage path lengths are $\mathrm{XLABEL}(J), I \leq J \leq \mathbb{N}$.

Yen!s contribution [6] to this search procedure is one of improved implementation. Rather than letting $J$ range from $I$ to $N$ at each stage and asking if each $J$ is temporary, Yen suggests the following coding device. Initialize $\operatorname{ITEMP}(I)=I, I \leq I \leq N$, and $K=\mathbb{N}-1$. The temporary nodes, then, are the first $K$ entries of ITEMP. While trying to reduce each temporary node label; keep track of the minimizing temporary node IP as well as its position IQ in ITEMP. Then, when IP is stored in IPERM, set $\operatorname{ITEMP}(\mathrm{IQ})=\operatorname{ITEMP}(\mathrm{K})$. This has the double effect of removing IP from ITEMP and leaving the new set of temporary nodes in the first $K$ entries of ITEMP. Yen's modification saves SPTH3 about $25 \%$ in run time. If, because of omissions in arc data, some node is isolated from the boundary, its infinite label will eventually become the least temporary 
label at some stage. When this happens, NE is set to zero and SPTH3 returns to the user, who must supply the missing data before trying again.

\subsection{Retracing the Shortest Paths}

Given the predecessors $\operatorname{NEXT}(\cdot)$ and possibly some predecessors in $\operatorname{NPOOL}(\cdot)$, SPTH3 can retrace the digraph $S$ of all the shortest paths from the boundary to the targets. No label-arithmetic is, needed. As each directed arc of $\mathrm{S}$ is obtained, it is stored as an ordered pair of integers in $\operatorname{IEDGE}(2, \cdot)$ and $\operatorname{IEDGE}(3, \cdot)$, and the $\operatorname{arc}^{\prime} \mathrm{s}$ region number is stored in $\operatorname{IEDGE}(1, \cdot)$. The retrace proceeds as follows.

Initialize $\mathrm{NE}=0$. Find the last target node in IPERM, i.e., the one furthest from the boundary, and set $J$ to this node number. Let $I=N E X T(J)$, the predecessor of $J$, assuming $J$ has only one. Add one to $N E$, and if $N E$ does not exceed MAXE, store arc $(I, J)$ and its region number in $\operatorname{IEDGE}(\cdot, \mathrm{NE})$. Now record the fact that a shortest sabotage path passes through I by negating ITEMP(I) if it is positive. If $J$ has another prederessonr, it is NPOOL(LINK), where LINK is packed in the upper portion if NEXT. $J$ ). In this . case, set $I=N P O O L(L I N K)$, repeat the above arc-storage process and continue until all the predecessors of $J$ contribute arcs to IEDGE. (Notice that all. the arcs of $S$ leading into $J$ are listed consecutively in IEDGE.) Set $J$ to the node in IPERM just before the one last used to set $J$, i.e., let $J$ range over the nodes in the order opposite that in which they were made permanent. If $\mathrm{J}$ is a target node or a barrier node with negative ITEMP $\left(\mathrm{J}^{\circ}\right)$, then repeat the above procedure for this new $J$. If $J$ is a boundary node or a barrier node that does not belong to a shortest sabotage path, then skip it, continuing until $J=\operatorname{IPERM}(I)$ has been treated.

Thus, IEDGE contains all the arcs in the digraph $S$ of all shortest sabotage paths. Moreover, the second nodes of these arcs occur in the 
order of nonincreasing distance from the boundary.

\subsection{Counting the Shortest Paths}

The fact that the second nodes in IEDGE have nonincreasing distance from the boundary allows the shortest paths to be counted quickly as follows. Set

$$
\operatorname{NPATH}(I)= \begin{cases}I, & \text { boundary node } \\ 0, & \text { barrier or target node. }\end{cases}
$$

Then for each arc $K$ in IEDGE, taken from bottom to top, i.e., from the boundary to the last target, set

$$
\begin{aligned}
I & =\operatorname{IEDGE}(2, \mathrm{~K}) \\
J & =\operatorname{IEDGE}(3, \mathrm{~K}) \\
\operatorname{NPATH}(J) & =\operatorname{NPATH}(J)+\operatorname{NPATH}(I), \quad \mathrm{K}=\mathrm{NE}, \ldots, \mathrm{I}
\end{aligned}
$$

The final value of $\operatorname{NPATH}(J)$ is just the sum of $\operatorname{NPATH}(I)^{\circ}$. over all the nodes $I$ in $S$ which have an arc leading to $J$. Notice that. each such node $I$ will have its final NPATH value computed before $\operatorname{NPATH}(I)$ is added to $\operatorname{NPATH}(J)$ because of the ordering of the arcs in IEDGE. Hence, NPATH(J), is the number of shortest. paths from the boundary to each node $J$ in $S$, in particular to $J=1,2, \ldots, N 1$. 


\section{Listing of SPTH3}

SUBROUT INE SPTH3 $(N 1, N 2, N 3, N A, W, M R, I I, J J, A W T, M A X E, I E D G E, N E, N S P$, 1 XMINL)

DIMENSION W(1),MR(1), II (1),JJ(1), AWT $(1), \operatorname{IEDGE}(3,1), N S P(1), X M I N L(1)$ COMMON XLABEL(155), NPATH(155), IPERM(155), ITEMP(155), NODE(155,4),

1 IREG $(82,2)$, NFXT (155), NPOOL (4ח)

SIMULTANEOUS SABOTAGE PROBLEM--ONE TEAM PER HARDWARE NODE - USES DI JKSTRA-TYPE SABOTAGE ALGORITHM--UNDIRECTED NODES, TIME WEIGHTS. SAVES SHORTEST PATHS FROM OFF-SITE TO EACH HARDWARE NODE. SPTH3 SEARCHES INWARD AND USES NO DISTANCE MATRIX. INIPUT.

NI NO. OF HARDWARE NODES.

N2 NO. OF BARRIER NODES.

N3 NO. OF BOUNDARY NODES.

NA NO. OF ARCS:

W NODE WEIGHT VECTOR, DIMENSIONED $N=N 1+N 2+N 3$ •

W IS CHANGED.

ARC DATA--FOUR NA VECTORS. ARCS MUST BE LISTED REGION BY REGION. FURTHERMORE, WITHIN EACH REGION HAVING P NODES THERE MUST BE $P *(P-1) / 2$ ARCS LISTED ROW BY ROW IN STRICTLY UPPER TRIANGULAR FORM. THAT IS, (II,I2), (11, I3), .., (II,IP), $(I 2, I 3), \ldots,(I 2, I P),(I 3, I 4), \ldots,(13, I P), \ldots$, (IPMI,IP).

MR REGION INDEX VECTOR •

II NODE INDEX VECTOR.

JJ NODE INDEX VECTOR •

AWT ARC WEIGHT VECTOR. AWT IS CHANGED.

MAXE MAXIMUM NO. EDGES (ARCS) IN THE DIGRAPH S OF SHORTEST PATHS

FROM OFF-SITE TO ALL HARDWARE NODES.

THIS VALUE IS THE SECOND DIMENSION OF IEDGE. OUTPUT.

IEDGE EDGFS, IN THE DIGRAPH S, THE UNION OF ALL GHORTEST PATHS DIRECTED FROM THE BOUNDARY TO ALL HAROWARE NODES. IEDGE WILL HOLD MAXE EDGES, EACH BEING GIVEN BY 3 INDICES -- THE REGION, AND TWO ORDERED NODES• THE EDGES ARE LISTED IN IEDGE SO THAT THE SECOND NODES HAVE A DECREASING DISTANCE FROM OFF-SITE.

WORK ARRAYS

NO. EDGES IN DIGRAPH S.

NSP NO. SHORTEST PATHS TO H, H=1,2, .., N .

XMINL LENGTH OF SHORTEST PATHS TO H, H=1,2,..,N1.

THE. DIMENSION OF NSP AND XMINL MUST BE AT LEAST AS LARGE. AS NI

MAXE IF MAXE $=0$ UPON EXIT, THERE WAS A FAILURE OF THE TRIANGLE

INEQUALITY ON THE ARC WEIGHTS OF A REGION, AND THE.

ALGORITHM WAS NOT FXECUTED.

FOUR VECTORS DIMENSIONED $N=N 1+N 2+N 3$.

XLAREL

TEMPORARY AND PERMANENT DISTANCE LABELS. THESE LABELS

REPRESENT THE LENGTH OF THE CURRENTLY SHORTEST

PATHS FROM OFF-SITE TO EACH NODE.

NPATH NUMBER OF SHORTEST PATHS FROM OFF-SITE TO EACH NODE OF $S$.

I PERM NODES WHERE DISTANCE LABELS HAVE BEEN MADE PERMANENT •

I TEMP NODES WHERE DISTANCE LABELS ARE STILL TEMPORARY.

NODE REGION AND LOCAL NODE NUMBERS FOR EACH NODE. DIMENSION $(N, 4)$. NODE (I, 1), NODE (1,3) ARE REgION NUMBERS FOR NODE I. NODE $(I, 2)$, NODE $(I, 4)$ ARF CORRESPONDING LOCAL NODE NUMBERS. 


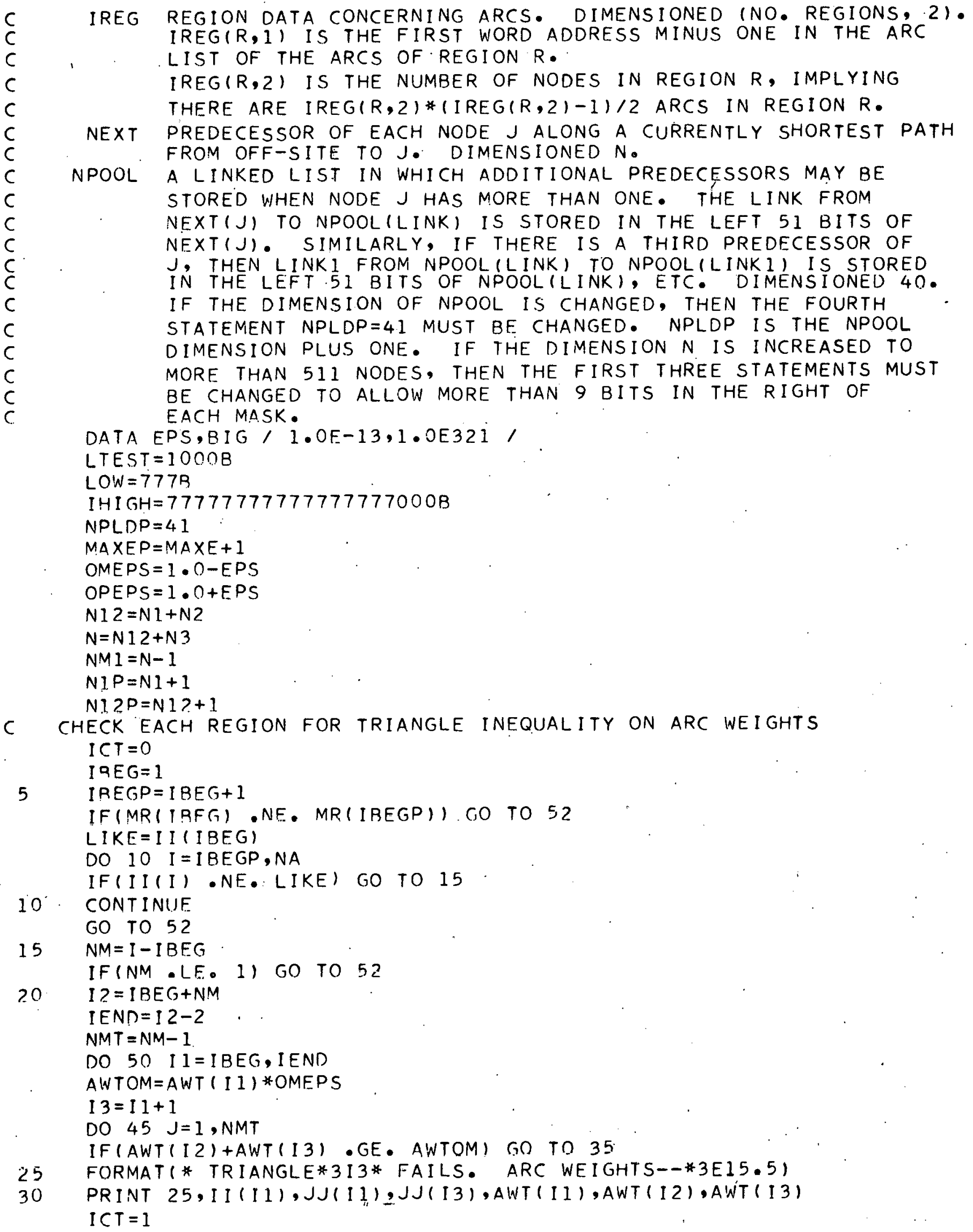




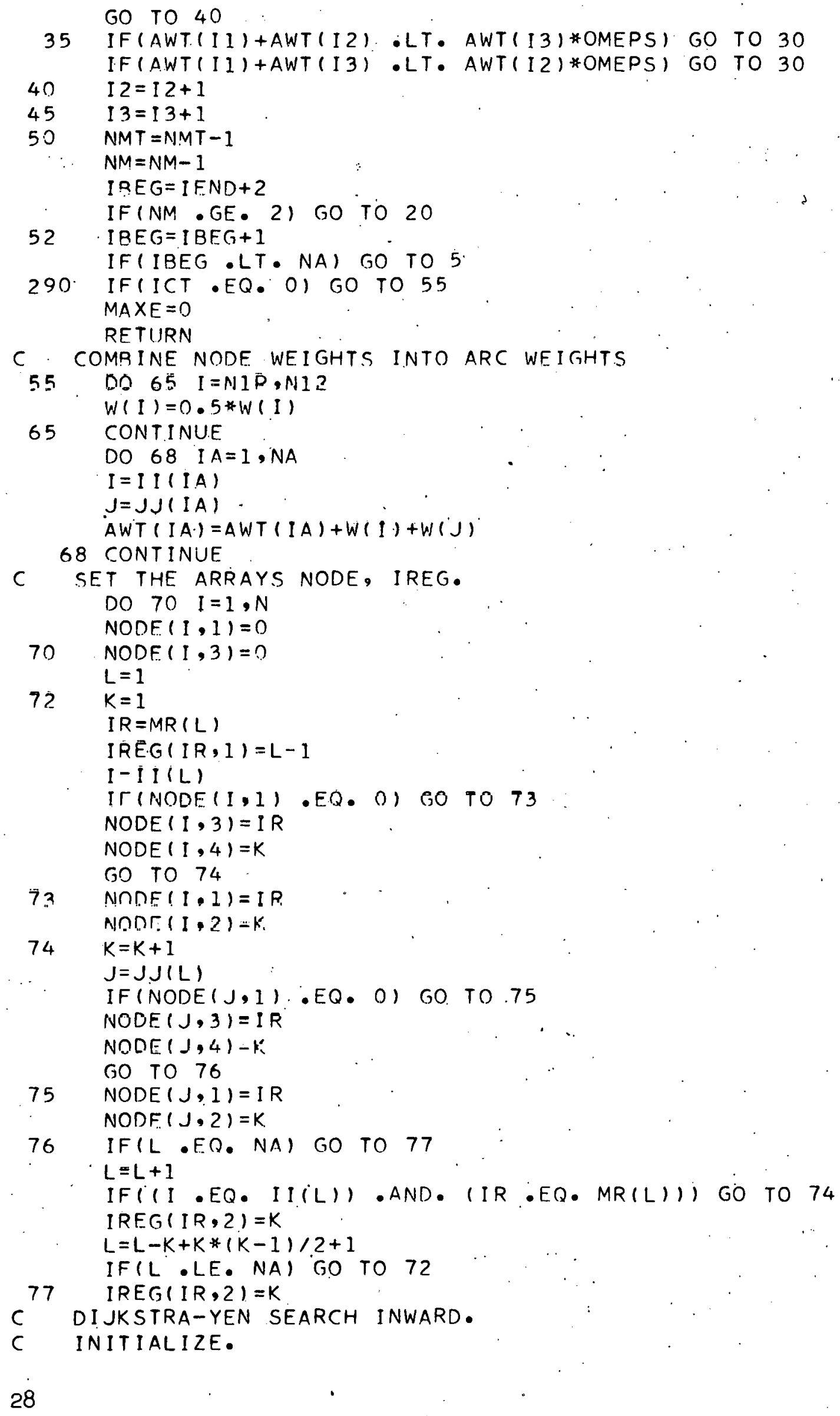




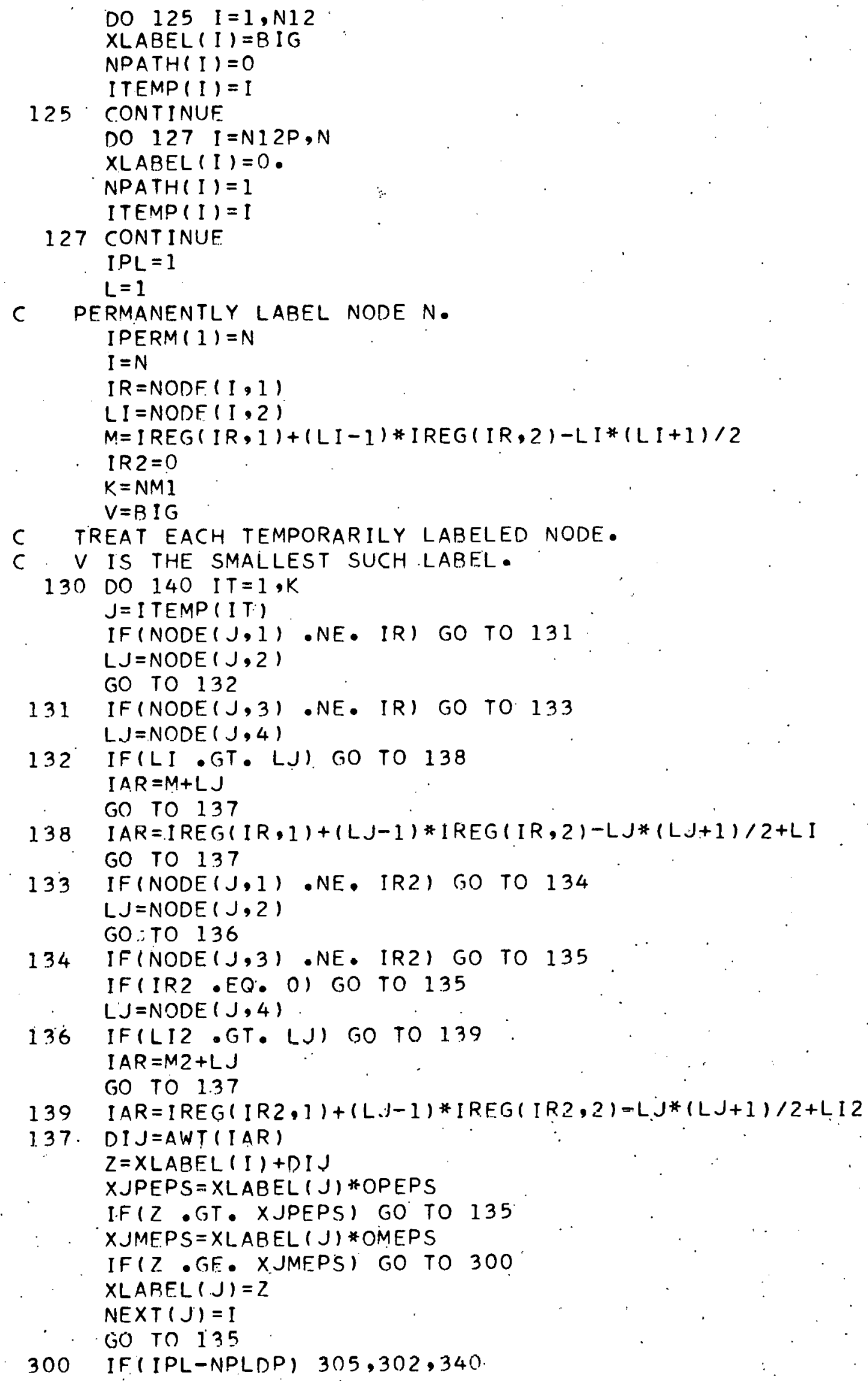


301 FORMAT ( NPOOL NEEDS TO STORE MORE LINKS*)

302 PRINT 301

GO TO 340

305. NPRED $=$ NEXT $(J)$

310 IF(NPRED . LT. LTEST) GO TO 320

LINK $=S H I F T(N P R E D$. AND・IHIGH,-9)

NPRED $=$ NPOOL $(L I N K)$

GO TO 310

320 NPOOL (IPL) $=1$

II = SHIFT $(I P L, 9): O R$. NPRED

IF (NPRED .EQ. NEXT(J)) GO TO 330

NPOOL ( LINK) $=$ I I

GO TO 340

$330 \quad N E X T(J)=11$

$340 \quad I P L=I P L+1$

135 IF (XLABEL (J) .GE. V) GO TO 140

$V=X L A B E L(J)$

$I P=J$

$I Q=I T$

140 CONTINUE

IF (V .NE. PIG) GO TO 155

NF: $=0$

DO . .5? $\mathrm{I}=1, \mathrm{NI}$

$\operatorname{NSP}(1)=0$

$X M I N L(I)=B I G$

152 CONTINUE

RETURN

C NODE IP IS TO BE PERMANENTLY LABELED.

$155 \quad V=B I G$

$L=L+1$

$\operatorname{IPERM}(L)=I P$

$I-I P$

IR-NODE (I,I)

$L I=N O D E(1,2$.

$M=I R E G(I R, I)+(L I-1) * I R F G(I R, 2)-L I *(L I+1) / 2$

$I R 2=N O D F(1,3)$

LI $2=\operatorname{NODE}(I, 4)$

$M 2=I R E G(I R 2,1)+(L I 2-1) * I R F G(I R 2, ?)-L I 2 *(L I>+1) / 2$

$J T E M P(I \cap)=I T E M P(K)$

$K=K-1$

IF $(K \cdot G T \cdot O)$ GO TO 130

C ALL NODES ARE PERMANENTLY LABELED.

C RETRACE AND STORE THE SHORTEST PATHS TO ALL' HARDWARE. NODES. $N[=0$

$180 \mathrm{~J}=\mathrm{IPERM}(\mathrm{L})$

$L=L-1$

IF(J.GT. N1) GO TO 180

182. $I=N E X T(J)$

183 NPRED $=i$

$I F(I \cdot G E \bullet L T E S T) I=I$.AND. LOW

$N E=N E+1$

IF (NE-MAXEP) $193,192,205$

191 FORMÁT * DIGRAPH OF SHORTEST PATHS CONTAINS MORE THAN* I 3: $\because$ 1 * EDGES*j

192 PRINT 191, MAXE 


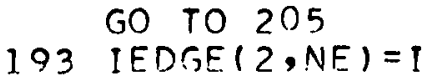

$$
\begin{aligned}
& \operatorname{IEDGE}(3, N F)=J \\
& I R=\operatorname{NODE}(J, I) \\
& I R 2=\operatorname{NODE}(J, 3) \\
& I F((N O D E(I, I), E Q . I R) \quad O O R \bullet(\operatorname{NODE}(I, 3) . \in E Q \cdot I R)) \quad I R 2=I R \\
& I E D G E(1, N E)=I R 2 \\
& I T=I T E M P(I) \\
& \text { IF(IT:GT:O) ITEMP(I) }=-I T \\
& 205 \text { IF ( I E EQ. NPRED) GO TO } 215 \\
& \text { LINK }=\text { SHIFT (NPRED.AND. IHIGH,-9) } \\
& I=N P O O L(L I N K) \\
& \text { GO TO } 183 \\
& 215 \text { IF(L . FQ. O) GO TO } 220 \\
& J=I \operatorname{PFRM}(L) \\
& L=L-1 \\
& \text { IF(J •LE. NI) GO TO } 182 \\
& \text { IF ( J .GT • NI2) GO TO } 215 \\
& \text { IF (ITEMP (J) :LT. O) GO TO } 182 \\
& \text { GO TO } 215 \\
& C \text { COUNT THE SHORTEST PATHS TO EACH HARDWARE NODE. } \\
& 220 \quad K=N E \\
& \text { DO } 225 \mathrm{~L}=1, \mathrm{NE} \\
& I=I E D G E(2, K) \\
& J=I E D G E(3, K) \\
& \text { NPATH }(J)=N P A T H(J)+N P A T H(I) \\
& \text { - } K=K-1 \\
& 225 \text { CONTINUE } \\
& \text { DO } 230 \quad I=1, N I \\
& \text { NSP (I) = NPATH(I) } \\
& X M I N L(I)=X L A R E L(I) \\
& 230 \text { CONTINUE } \\
& \text { RETIIRN. } \\
& \text { END }
\end{aligned}
$$




\section{Acknowledgements}

We want to thank S. I. Daniel, 5'll1, and G. B. Varnado, 54le, for supplying us with some of the test problems and for their helpful comments concerning the use of SPTH3.

\section{REFERENCES}

[1] H. A. Bennett, The "EASI" Approach to Physical Security Evaluation, SAlND6-0500, Sandia Laboratories, Albuquerque, New Mexico, January 1977.

[2] L. D. Chapman, Effectiveness Evaluation of Alternative Fixed-Site Safeguard Security Systems, SAND75-6159, Sandia Laboratories, Albuquerque, New Mexico, July 1976.

[3] E. W. Dijkstra, A Note on Two Problems in Connexion with Graphs, Numer. Math. I, 269-271 (1959).

[4] B. L. Hulme, Patht'inding in Graph-Theoretic Sabotage Models. I. Simultaneous Attack by Several Teams, SAND76-0314, Sandia Laboratories, Albuquerque, New Mexico, July 1976.

[5] T. A. Williams and G. P. White, A Note on Yen's Algorithm for Finding the Length of All Shortest Paths in N-Node Nonnegative-Distance Networks, J. Assoc. Comput. Mach. 20, 389-390 (1973).

[6] J. Y. Yen, Finding the Lengths of All Shortest Paths in N-Nore Nonnegative-Distance Complete Networks Using $\frac{1}{2} N^{3}$ Additions and $\mathrm{N}^{3}$ Comparisons, J. Assoc. Comput. Mach. 19, 423-424 (1972). 
DISTRIBUTION :

USNRC Distribution Section Attn: Robert Wade Washington, DC 20555 NRC-13 (208)

1000 G. A. Fowler

1140 W. D. Weart

1141 I. R. Hill

1141 D. B. Holdridge (10)

1230 W. L. Stevens

1233 R. E. Smith

1233 M. D. Olman

1310. A. A. Lieber Attn: W. F. Roherty, 1311

1700 0. E. Jones

1710 V. E. Blake

1712 J. W. Kane

$1738 \mathrm{~J}$. Jacobs

1739 J. D. Williams

1739 D. L. Mangan.

1750 J. E. Stiegler

I750A M. N. Cravens

$1750 \mathrm{~A}$ J. M. Demontmollin

1751 T. A。 Sellers

1751 J. L. Darbey

1751 B. R. Fenchel

1751 L. C. Nogales

1751 A. E. Winblad

1752 M. R. Madsen

1754 J. F. Ney

1754 J. L. Todd, Jr.

1758 T. J. Hoban

1758 D. D. Boozer

1758 R. C. Hall

1758 G. A. Kinemond

1758 W. K. Pa,llus

1758 I. G. Waddoups

1758 R. B. Worrell

4010 C. Winter

5000 A. Narath, Attn: Directorates 5200, 5800

5100 J. K. Galt

5110 F. L. Vook

51.20 G. J. Simmono

5121 R. J. Thompson

5121 P. .T. Slater

5122 L. F. Shampine

5122 B. L. Hulme (50)

5130 G. A. Samara

5150 J. E. Schirber

5160 W. Herrman

5400 A. W. Snyder

5410 D. J. McCloskey

5411 S. L. Daniel
5412 J. W. Hickman

5412 D. E. Bennett

5412 D. M. Ericson, Jr.

5412 G. B. Varnado

5700 J. H. Scott

5740 V. I. Dugan

5741. L. D. Chapmen

5741 K. G. Adams

5741 H. A. Bennett

5741 D. Engi

57.41 L. M。 Grady

5741 R. D. Jones

5741 R. G. Roosen

5741 D. W. Sasser

.5741 A. A. Trujillo

5742 S. G. Varnado

8300 B. F. Murphey

8320 T. S. Gold

8321. R. L. Rinne

8266 E. A. Aas (2)

3141. C. A. Pepmueller (Actg.)

3151 W. L. Garner (3) For ERDA/TIC (Unlimited Release)

3171-I R. Campbell (25) For ERDA/TIC 